\title{
Bolivia en el comercio mundial: entre la globalización y la marginalización
}

\author{
Ramiro Orias Arredondo
}

La globalización de los mercados, la producción, las inversiones y las finanzas constituyen una de las tendencias internacionales más relevante. Los países en desarrollo que no logran insertarse positivamente en las corrientes más dinámicas de la economía global corren ei riesgo de verse cada vez más marginados. En este contexto, se evalúa la posición de Bolivia en el comercio mundial y la naturaleza de sus relaciones comerciales. Se analizan las reformas económicas que se han realizado en.los últimos años, así como se identifican variables estructurales internas que afectan su articulación con el exterior. Finalmente, el autor concluye que las características especiales de su estructura económica nacional han condicionado su modalidad de inserción en los mercados internacionales, generando una difícil contradicción al coexistir un alto grado de apertura externa oficial y un bajo nivel de competitividad internacional. El país se encuentra, entonces, tensionado por dos fuerzas contrapuestas: el desafío de la globalización y la fatalidad de la marginalización. La manera de superar esta dicotomía dependerá de cómo se enfrente el proceso de transformación productiva de su economía.

\section{Introducción.}

El escenario económico internacional está viviendo un proceso de transición y transformación. Una de las tendencias más relevantes constituye la globalización de los mercados, la producción, las inversiones y las finanzas. Sin embargo, la economía boliviana se debate aún frente a corrientes de marginalización y aislamiento en sus vinculaciones en el comercio internacional.

En este estudio, se analiza la situación del comercio exterior boliviano ante la creciente globalización del comercio internacional y se estudian las características más importantes de la estructura económica nacional y su relación con el comercio exterior. Luego, se puntualiza el impacto 
de la economía subterránea en nuestro relacionamiento externo y, finalmente, se ven los cambios introducidos en la política comercial por la llamada Nueva Política Económica. Por último, se concluye sintetizando los problemas y perspectivas que debe afrontar la economía boliviana para mejorar su presencia en el comercio internacional.

\section{Bolivia en el comercio internacional.}

Las relaciones económicas internacionales de cada país constituyen un ámbito donde se articulan sus condiciones internas con los factores externos y el tipo de relaciones que se genere entre estos elementos determinará las modalidades que ese país adopta en su inserción internacional y patrón de desarrollo nacional.

El patrón de desarrollo e inserción externa en Bolivia ha estado estrechamente vinculado con la explotación de recursos naturales no renovables, lo que no es sostenible en el muy largo plazo. Más aún si consideramos que las materias primas en su conjunto están atravesando un proceso paulatino de pérdida de importancia relativa en el comercio mundial. Su principal consecuencia es la caída constante en los índices de relación de intercambio. Entre 1980 a 1993, ha existido un deterioro estimado de 100 a 37,9 en la relación de precios de intercambio. ${ }^{1}$

El comercio boliviano se orienta fundamentalmente a países de ALADI, en menor medida a los de la Unión Europea y el NAFTA, y en último lugar de manera casi insignificante al Asia. En los últimos años Bolivia ha ido conectando de manera asimétrica su economía dependiente con países periféricos, y en estos no ocupa un lugar de gran importancia, ${ }^{2}$ por lo que este proceso de marginalización de la economía boliviana ha sido definido por Gustavo Fernández como: "Bolivia, país periferie de la periferie". Este autor sostiene que los "datos del comercio exterior confirman la tendencia de marginación de los circuitos de comercio mundial y la creciente latinoamericanización de sus vínculos económicos". Pero este proceso es de características más dramáticas: "la

\footnotetext{
${ }^{1}$ Banco Central de Bolivia, Boletín del Seclor Externo, N¹0, La Paz, diciembre de 1993, p. 100.

${ }^{2}$ El caso de las relaciones comerciales con Argentina ejemplifican bien esta situación. En 1980, las exportaciones bolivianas a ese pais representaban el $23,7 \%$ del total, pero para Argentina significaron el 2,2\% de sus importaciones. En 1991, el país patagónico concentró el 30,5\% de las exportaciones bolivianas, pero estas representaron el 2,92\% del total importado y en 1992 significaron el $1,1 \%$ de sus importaciones. Por otra parte, las exportaciones argentinas a Bolivia significaron el 1,6\% en 1980 y el $0,5 \%$ en 1990 del total exportado. Fuente: CEPAL, Anuario Estadístico de América Latina, 1993.
} 
relación asimétrica y la especialización desventajosa que caracterizó la relación nacional con los centros industrializados, se reproduce ahora en escala latinoamericana." 3

\section{Estructura geográfica del comercio exterior boliviano} (en porcentajes)

\section{Exportaciones}

$\begin{array}{lrrrrrrrr}\text { ZonasLAños } & 1970 & 1975 & 1980 & 1985 & 1990 & 1994 & 1995 & 1996 * \\ \text { ALADI } & 9,3 & 34,3 & 37,8 & 60,6 & 44,6 & 40,3 & 37,0 & 42,4 \\ \text { EEUU } & 34,8 & 30,4 & 25,7 & 13,5 & 19,9 & 29,4 & 28,7 & 20,0 \\ \text { Unión Europea } & 41,6 & 20,8 & 19,5 & 20,4 & 28,9 & 26,8 & 21,2 & 25,1 \\ \text { Asia } & 9,6 & 3,5 & 0,9 & 0,3 & 0,9 & 0,7 & 0,6 & 0,4 \\ \text { Resto del Mundo } & 5,7 & 11,0 & 16,1 & 5,2 & 5,7 & 2,8 & 12,5 & 12,1 \\ \text { Total } & 100,0 & 100,0 & 100,0 & 100,0 & 100,0 & 100,0 & 100,0 & 100,0\end{array}$

\section{Importaciones}

$\begin{array}{lrrrrrrrr}\text { Zonas\Años } & 1970 & 1975 & 1980 & 1985 & 1990 & 1994 & 1995 & 1996^{*} \\ \text { ALADI } & 17,5 & 30,3 & 37,8 & 44,7 & 45,9 & 44,1 & 38,5 & 41,0 \\ \text { EEUU } & 33,9 & 26,9 & 25,7 & 20,3 & 21,9 & 18,9 & 22,0 & 21,9 \\ \text { Unión Europea } & 23,9 & 20,8 & 19,5 & 17,4 & 14,5 & 11,9 & 16,3 & 12,5 \\ \text { Asia } & 12,3 & 15,1 & 9,9 & 10,4 & 11,4 & 17,7 & 15,2 & 16,7 \\ \text { Resto del Mundo } & 12,4 & 6,9 & 7,1 & 7,2 & 6,3 & 7,4 & 8,0 & 7,9 \\ \text { Total } & 100,0 & 100,0 & 100,0 & 100,0 & 100,0 & 100,0 & 100,0 & 100,0\end{array}$

Fuente: Elaboración propia basada en cifras del BCB - INE.

* 1er. Sem. 1996.

Como se ve en el cuadro anterior, el comercio exterior boliviano se orienta de manera predominante a los mercados de los países vecinos. Siendo que la economía latinoamericana sufre un proceso gradual de deterioro de su participación conjunta en el comercio mundial, las exportaciones bolivianas tienen su mayor destino en estos mercados de bajo dinamismo, no pudiendo escapar del estancamiento relativo y la marginalización. ${ }^{4}$ Bolivia se especializa en el comercio internacional preponderantemente en rubros declinantes y se relaciona principalmente

${ }^{3}$ Gustavo Fernández, "Condicionantes externos del desarrollo de Bolivia", FORO POLITICO N"6, Contexto Internacional y Politico en Bolivia, ILDIS, La Paz, 1989, p. 58.

${ }^{4}$ Entre 1950 a 1990 descendió la participación relativa de la región en el coniercio internacional. Las exportaciones cayeron desde un $12,4 \%$ a representar sólo el $3,9 \%$ del total de las exportaciones mundiales. En el mismo período las importaciones latinoamericanas descendieron del $10,1 \%$ al $3,2 \%$ de las importaciones mundiales. United Nations, International Trade Statistics Yearbook 1992, Vol. I, NY, 1993, pp. 28-29. 
con economías rezagadas, alejando su presencia de los circuitos más dinámicos del comercio mundial, lo que está generando un patrón de inserción externa declinante y difícilmente sostenible en el largo plazo.

Cabe anotar que en los últimos años, de manera un tanto más atenuada, la tendencia en la distribución geográfica del comercio persiste favoreciendo a los paises de la ALADI. Sin embargo, si en los porcentajes señalados para 1995 descontamos las exportaciones de gas a su único mercado, Argentina (que abultan el baremo de ALADI) por una parte, y agregamos Canadá y México con los Estados Unidos en torno al NAFTA por otra, y finalmente, sumamos las cifras de la Unión Europea con las de la EFTA, la realidad nos muestra un cuadro diferente: América del Sur (sin gas) $30,7 \%$; NAFTA $30,8 \%$; y una Europa ampliada $28,1 \%$. No cabe duda, de que se está gestando un nuevo proceso de equilibrio y diversificación de las exportaciones bolivianas en los mercados de occidente. El desafío de llegar al lejano oriente cruzando el Pacífico aún está pendiente, aunque es notable el crecimiento de las importaciones originadas en esa región.

Bolivia ha ido reduciendo su porcentaje de participación en el comercio mundial de un $0,12 \%$ en 1950 a sólo un $0,02 \%$ en 1995 . Este fenómeno se da en el marco del rezago comercial y declinación de los intercambios que afecta a los países en desarrollo, así como de la paulatina caída de las exportaciones tradicionales desde 1990, como producto de la baja de precios internacionales de minerales y el gas natural. En la última década los oscilatorios repuntes de las exportaciones no tradicionales no han contribuido significativamente a revertir esta situación.

Siguiendo el criterio propuesto en un interesante estudio de la CEPAL, ${ }^{5}$ que propone un modelo de medición y análisis de la competitividad de los países, resulta que la posición competitiva de Bolivia en la OCDE es extremadamente limitada y reducida. En 1990 Bolivia representó el $0,01 \%$ de todas las importaciones realizadas por los países

\footnotetext{
${ }^{5}$ CEPAL, Equidad y Transformación Productiva: Un Enfoque Integrado, \# LC/G.1701 (SES.23/3), Santiago de Chile, febrero de 1992, pp. 109-139. La competitividad internacional de las exportaciones de un pais está definida por los conceptos de posicionamiento y eficiencia. Por posicionamiento se entiende el dinamismo de un rubro exportado por un país en el total de las importaciones de los mercados internacionales más importantes (OCDE), que puede ser favorable y desfavorable, según aumente o disminuya. Por eficiencia se entiende la participación relativa de un pais en el total importado por los principales mercados (OCDE) de un rubro determinado, que puede ser alta o baja, según aumente o disminuya. Pudiendo entonces plantearse, según se combinen los caracteres de cada concepto, situaciones tipo que distinguen los elementos de competitividad creciente o decreciente en el desempeño comercial de un país.
} 
de la OCDE. Este índice refleja una pérdida de competitividad en los principales mercados internacionales, ya que sólo una década atrás, en 1980, la participación boliviana en el mercado de la OCDE representaba el $0,04 \%$. Los principales rubros exportados por Bolivia a dicho mercado se concentran en recursos naturales y productos semielaborados basados en recursos naturales, sectores que han perdido participación en el conjunto de las importaciones de los países de la OCDE. En ese período, hubo una sensible caída prácticamente en todos los rubros exportados por Bolivia a dicho mercado, excepto en el rubro de oro no monetario y joyas de oro y plata, que son clasificados como otros y manufacturas no basadas en recursos naturales respectivamente. A no ser el caso del estaño boliviano, que representa el $6,41 \%$ de las importaciones de ese mineral por países de la OCDE, en todos los demás rubros Bolivia representa menos de $1 \%$ de las respectivas importaciones de esos mercados. $^{6}$

\section{Bolivia: posición competitiva en la OCDE (\% participación en el mercado de OCDE)}

\begin{tabular}{llcc}
\multicolumn{1}{c}{ Grupo } & $\mathbf{1 9 8 0}$ & $\mathbf{1 9 9 0}$ & \multicolumn{1}{c}{$\%$} \\
*Recursos naturales & 0,05 & 0,03 & $(-42 \%)$ \\
- Agricultura & 0,02 & 0,02 & $(-7 \%)$ \\
- Energia & 0,00 & 0,00 & $(-85 \%)$ \\
- Fibras textiles, minerales & 0,49 & 0,19 & $(-61 \%)$ \\
*Manufacturas & 0,03 & 0,01 & $(-75 \%)$ \\
- Basadas en RRNN & 0,23 & 0,06 & $(-73 \%)$ \\
- No basadas en RRNN & 0,00 & 0,00 & $(-2 \%)$ \\
*Otros & 0,02 & 0,12 & $(581 \%)$ \\
*Total & 0,04 & 0,01 & $(-59 \%)$
\end{tabular}

Fuente: CEPAL, CAN, 1994.

Bajo este marco teórico, Bolivia muestra un modo de inserción externa de competitividad decreciente al presentar un posicionamiento desfavorable y un bajo nivel de eficiencia en los principales rubros exportados. Existe una declinación constante, en términos relativos del dinamismo y participación de las exportaciones mineras e hidrocarburos,

\footnotetext{
${ }^{6}$ Para profundizar el estudio sobre la posición competitiva de los principales rubros exportados por Bolivia véase la fuente de este acápite, ALADI, Propuestas para la reconversión industrial de Bolivia, BO/94/01, División de Promoción Económica, Publicación ND5, Montevideo, mayo, 1995, pp. 60-69.
} 
que como todos los productos primarios sin valor agregado sufren un proceso de deterioro. Cabe notar que el peso de este deterioro no sólo afecta a determinados rubros, sino al promedio global de la participación relativa del total de las exportaciones bolivianas.

El sector más dinámico del comercio internacional está centrado en los bienes manufacturados en los que se incorpora o interviene innovación tecnológica. En Bolivia la participación del sector industrial alcanza al 13,7\% del PIB, uno de los grados de industrialización más bajos de Latinoamérica. En el total de las exportaciones bolivianas las manufacturas industrializadas más complejas no basadas en recursos naturales y con incorporación de tecnología representan aproximadamente menos del $1 \%$, ya que la mayor parte de las exportaciones no tradicionales, que si bien tienen un componente de valor agregado, básicamente constituyen recursos agropecuarios en bruto o de escaso o simple procesamiento, to que representa bien la poca incorporación de tecnologías sofisticadas en la producción de los rubros exportables, evidenciando el perfil liviano de la industria nacional.

Una de las tendencias del mercado mundial es la falta de dinamismo y declinación relativa de los productos básicos. Es decir, esta condición externa conduce a que Bolivia genere niveles de participación y desempeño comercial inferiores a otros países que sí logran insertarse en circuitos más dinámicos. Esto está llevando al país no sólo al deterioro de su participación en las exportaciones mundiales, sino a la pérdida de su articulación global con la economía mundial.

Así, si se analiza la posición de Bolivia en el comercio global y la naturaleza de sus relaciones comerciales, se constata que ocupa un lugar cada vez más marginal. Esto está llevando a la declinación de su presencia relativa y deterioro de su participación en la economía mundial. Dadas las tendencias internacionales, este proceso de marginalización puede generar una situación de aislamiento económico internacional incluso más perjudicial que el territorial. El país ha ido perdiendo paulatinamente su capacidad de sostener relaciones comerciales satisfactorias, dinámicas, competitivas, estables, constantes, múltiples y diversificadas en el tiempo.

\section{Estructura económica nacional y comercio exterior.}

Las especiales características de la estructura económica nacional han condicionado la modalidad de la inserción boliviana en los mercados 
internacionales. Desde la explotación colonial de las ricas minas de plata, de estaño en la mayor parte de este siglo y de gas natural durante los últimos años, se muestra una constante en la historia económica de Bolivia: la actividad extractiva de recursos naturales ha sido siempre el pilar de su economía y de su inserción comercial externa. La estructura económica boliviana se caracteriza por la producción de pocos productos primarios, lo que ha determinado su especialización en el comercio internacional.

Bolivia primordialmente depende de la explotación y exportación de hidrocarburos y minerales, así como de la producción de una escasa gama de productos agrícolas. Hasta mediados de la década del sesenta sólo las exportaciones de estaño concentraban aproximadamente el $70 \%$ de las exportaciones totales de Bolivia, situación que marcaba al país como una economía cuasi-monoexportadora. Sin embargo, a partir de 1965 el estaño con fluctuaciones empezó a declinar en el mercado mundial, impactando en la naturaleza productiva del país. Esto motivó un proceso de điversificación y sustitución de exportaciones. En principio se amplió la participación de otros recursos mineralógicos (zinc) en las exportaciones mineras, luego en los setenta se amplió aún más la composición de las exportaciones tradicionales, incrementando la participación de los hidrocarburos. A partir de 1985 se expanden las exportaciones no tradicionales, que de significar el 3,7\% de las exportaciones totales de 1984, para 1994 se estima que representan el $48,6 \% .{ }^{7}$ No obstante, en la nueva estructura exportadora el mayor peso sigue centrado en materias primas con escaso valor agregado nacional.

En Bolivia las exportaciones tradicionales siempre han tenido el mayor peso relativo. Así, "las exportaciones de estaño, zinc y gas natural, han constituido en promedio anual el $64 \%$ del valor de las exportaciones legales entre 1950 y $1990^{\prime \prime} .8$ Sin embargo, el desempeño de 1994 es histórico; si bien las exportaciones tradicionales concentran el 51,4\% del total exportado ese año, al desagregar ese dato se observa que el $48,6 \%$ representa las no tradicionales. Por primera vez en los últimos 400 años, Bolivia ha superado la participación porcentual de los minerales $(41,5 \%)$, rompiendo la tradición exportadora de país eminentemente minero.

\footnotetext{
${ }^{7}$ En 1993 seis productos (soya, artículos de joyerla, madera, azúcar, castaña y cueros) concentraban el $76 \%$ del total de exportaciones no tradicionales.

${ }^{8}$ Víctor H. Morales, "Las exportaciones bolivianas y la política económica de 1985", Opinión, Cochabamba, 4 de enero de 1995, p. 8.
} 
La inestabilidad de las exportaciones no tradicionales es una amenaza muy sensible y latente, puesto que estas se concentran en productos agrícolas y semielaborados, cuyo desempeño está muy determinado por las condiciones climáticas y los cambiantes precios internacionales de dichos productos.

\section{Evolución de la estructura de las exportaciones (en porcentajes)}

$\begin{array}{cccr}\text { Años/Productos } & \text { Minería } & \text { Hidrocarburos } & \text { No Tradicion } \\ 1984 & 46,5 & 49,7 & 3,7 \\ 1985 & 39,2 & 55,7 & 5,1 \\ 1986 & 30,9 & 52,1 & 17,0 \\ 1987 & 36,4 & 45,0 & 18,7 \\ 1988 & 45,5 & 36,5 & 18,0 \\ 1989 & 49,1 & 26,0 & 24,9 \\ 1990 & 43,9 & 24,5 & 31,6 \\ 1991 & 42,0 & 28,4 & 29,6 \\ 1992 & 53,3 & 17,7 & 29,0 \\ 1993 & 48,0 & 12,8 & 39,2 \\ 1994 & 41,5 & 9,8 & 48,6 \\ 1995 & 43,6 & 12,9 & 43,5 \\ 1996\left(^{*}\right) & 43,0 & 12,4 & 44,7\end{array}$

Fuente: Banco Central de Bolivia, Boletin del Sector Externo, №15, La Paz, junio de 1996. p. 28.

$\left(^{*}\right)$ Estimación para enero-junio/96.

En 1980, las exportaciones totales sumaron 1.036 millones de dólares y el desempeño de 1995 alcanza a los 1.100 millones. Luego de 15 años se logra superar el récord histórico exportado en 1980, en una situación en que el dólar está cada vez más depreciado internacionalmente.

Respecto a la participación del sector público y privado en el total de las exportaciones, en 1984 cuando se inicia el colapso del modelo estatista, el sector privado participó con $11,4 \%$, mientras que el sector público absorbía el $88,6 \%$. Luego de 10 años de transformaciones estructurales, en 1993 la relación se invierte y mientras el sector privado genera el $75 \%$ de las exportaciones, el público contribuye con sólo el $25 \%$. Esta realidad se debe al paulatino retiro del Estado de la economía y la caída de los precios internacionales de los minerales y del gas natural. De manera concomitante, se evidencia una mayor participación de la 
minería mediana privada en las exportaciones de nuevos minerales y una creciente participación empresarial en las exportaciones no tradicionales.

Así, de 327 empresas privadas que realizaron este tipo de operaciones en 1987, para 1994 se incrementó a 485 unidades. Sin embargo, la actividad exportadora presenta la siguiente dicotomía: un grupo de 403 empresas, que representan $82,9 \%$ de los exportadores, exportan el $15,1 \%$ de productos no tradicionales. Mientras otro grupo de 82 empresas el $17,1 \%$ de los exportadores envía el $84,9 \%$ de las exportaciones no tradicionales.

La situación es más crítica en el sector industrial en el cual, de acuerdo al II Censo de Establecimientos Económicos de 1992, de las 14.389 empresas existentes en la industria, sólo el 1,5\% realizaba ese año algún nivel de ventas para el mercado externo. Esta alta concentración de las exportaciones en pocas empresas muestra que aún esta actividad no multiplica y difunde sus beneficios entre la mayoría de los sectores de la sociedad.

Si analizamos la composición de las importaciones, es notoria la participación de los bienes de capital, que si bien significa absorción de tecnología e inversión productiva, también muestra una creciente dependencia tecnológica-externa, que asigna un rol marginal de explotadores y proveedores de recursos naturales. La naturaleza de la composición de las importaciones muestra bien las carencias productivas, industriales y tecnológicas, reflejando el bajo índice de industrialización del aparato productivo.

En 1993, el sector industrial contribuyó con el 13,7\% del Producto Nacional, el índice más bajo de América del Sur. ${ }^{9}$ Ese año el 58,5\% del valor agregado industrial se concentró en las industrias productoras de alimentes-y-bebidas-que-son-rubres-poco-dinámicos en el comereio internacional. El desempeño productivo de la industria se caracteriza por su reducida participación en la economía nacional y por su baja diversificación, que concentra su producción en bienes de consumo no durables y de bajo dinamismo orientados principalmente al mercado local y es más bien importadora de bienes con mayor valor agregado. Así, la

\footnotetext{
${ }^{9}$ Adicionalmente, cabe considerar que en el periodo $1985-90$ las exportaciones de manufacturas contribuyeron al $0,3 \%$ deJ $\mathrm{PIB}$, significaron el $2,8 \%$ del total de las exportaciones bolivianas y contribuyeron con menos del $0,05 \%$ de las exportaciones de América Latina, representando los indices más bajos de la región. BID, Informe 1993, p. 283.
} 
reconversión industrial ocupa un lugar de privilegio en lo que debería ser la agenda de su transformación productiva. ${ }^{10}$

\section{Evolución de la estructura de las importaciones (en porcentajes)}

$\begin{array}{cccc}\text { Año/Productos } & \begin{array}{c}\text { Bienes de } \\ \text { Consumo }\end{array} & \begin{array}{c}\text { Bienes } \\ \text { Intermedios }\end{array} & \begin{array}{c}\text { Bienes de } \\ \text { Capital }\end{array} \\ 1984 & 19,4 & 41,6 & 37,9 \\ 1985 & 19,3 & 40,3 & 36,4 \\ 1986 & 19,8 & 34,9 & 41,8 \\ 1987 & 24,8 & 40,0 & 34,3 \\ 1988 & 21,7 & 38,7 & 39,3 \\ 1989 & 22,5 & 40,8 & 36,1 \\ 1990 & 22,2 & 36,9 & 39,4 \\ 1991 & 21,2 & 36,2 & 39,6 \\ 1992 & 18,8 & 35,3 & 43,1 \\ 1993 & 20,1 & 35,1 & 43,0 \\ 1994 & 25,8 & 38,5 & 35,1 \\ 1995 & 27,5 & 39,5 & 33,0 \\ 1996^{*} & 26,0 & 39,8 & 35,2\end{array}$

Fuente: Banco Central de Bolivia, Boletín del Sector Externo, N¹5, La Paz, junio de 1996, p. 49.

$\left.{ }^{*}\right)$ Estimación para enero-junio/96.

En una economía mundial como la actual, el desarrollo nacional está ligado al tipo de inserción internacional que adopta cada país. El comercio exterior de los países está condicionado por las ventajas competitivas que pueda desarrollar internamente. El lograr altos niveles de competitividad internacional, no sólo comprende a los niveles de productividad y calidad de sus productos, sino a múltiples factores económicos y extraeconómicos de tipo doméstico, que hacen el entorno competitivo del país en su conjunto: estabilidad política, modernidad empresarial y solidez institucional, equilibrio macroeconómico, clima de inversión, infraestructura y comunicaciones, progreso tecnológico, desarrollo de los recursos humanos, financiamiento, etc. En ese sentido, consideramos que se ha avanzado bastante en el fortalecimiento democrático, la estabilidad económica y las reformas institucionales; sin embargo, resta aún ${ }^{10} \mathrm{Al}$ respecto véase el interesante trabajo-diagnóstico de ALADI, "Propuestas para la Reconversión Industrial de Bolivia", BO/94/01, Publicación N5, Montevideo, mayo de 1995. 
desarrollar ventajas competitivas en el área de infraestructura física, financiamiento, telecomunicaciones, desarrollo tecnológico, salud y educación.

\section{Economía informal y economía ilegal.}

El estudio de las relaciones económicas internacionales de Bolivia sería incompleto sino incluimos algunas consideraciones sobre determinadas relaciones transnacionales de tipo informal e ilegal, que no se registran en las cuentas nacionales, pero que sin embargo tienen un importante impacto sobre la economía nacional, distorsionan el comercio exterior y generan un entorno corruptor que erosiona la legitimidad de las estructuras estatales. Es el caso de las actividades vinculadas al contrabando y al narcotráfico, 11 que económicamente se expresan respectivamente como importaciones informales y exportaciones ilegales, pero que dado ese su carácter es muy difícil de contar con información estadística veraz. A pesar de que existen limitaciones de orden conceptual y metodológico en las proyecciones, aludiremos a algunas estimaciones para mostrar las dimensiones y proporciones que asumen ambas actividades.

Para tener una idea de su importancia, según estimaciones del CEDLA, los datos censales de 1976 muestran que un 42,6\% de la Población Económicamente Activa Urbana pertenecía al sector informal, cifra que en 1988 se incrementó al 54,6\%. De mantenerse las mismas condiciones, el año 2.000 se estima que un $69 \%$ de la PEAU estará trabajando en ese sector. ${ }^{12}$ El sector informal participa en el PIB como mínimo con el $11,4 \%$ del producto. ${ }^{13}$

El fenómeno del contrabando, que define a la irregular internación al país de mercaderías sujetas a fiscalización aduanera, ha generado en Bolivia una realidad de comercio informal y evasión impositiva de grandes magnitudes, que compite con el sector formal en condiciones de competencia desleal y desigual, ocupando el primer lugar de la actividad

\footnotetext{
"Siguiendo el criterio de H. de Soto expuesto en su obra El Otro Sendero, la economía informal es un "sistema ilegal para lograr fines legales", concepto que comprende bien al contrabando y no ast al narcotráfico, que en nuestro criterio cae dentro lo que es una economía ilegal, constituyendo un sistema ilegal para el logro de fines tambièn ilegales. Aunque ambos pueden ser componentes de un concepto más genérico, economía subterránea, que alude a toda actividad económica que no es cuantificada por los registros oficiales.

${ }^{12}$ CEDLA, "Informalidad e ilegalidad: Una falsa identidad", Opinión, Cochabamba, 31 de mayo de $1989, \mathrm{p} 11$.

${ }^{13}$ Muller \& Asociados, "Sector Informal y Crecimiento Económico en Bolivia", Informe Confidencial 1991, La Paz, febrero de 1992.
} 
informal que se da en el país. La magnitud económica del contrabando varía mucho: según la fuente, en 1992 la Unidad de Análisis y Políticas Económicas del Ministerio de Planeamiento lo proyectó en 280 millones de dólares; ${ }^{14}$ según estimaciones de la Dirección General de Aduanas el contrabando que ingresa al país alcanzaría a los 350 millones de dólares; ${ }^{15}$ y la Cámara Nacional de Industria para ese mismo año lo estimó en 800 millones de dólares. ${ }^{16}$ Según algunos analistas el contrabando corresponde, como mínimo a una mitad de las importaciones anualmente. ${ }^{17}$

La realidad cotidiana de las principales ciudades de Bolivia es evidencia patética del crecimiento de este sector. Dada la estructura importadora de la economía boliviana, el mayor desarrollo de actividades informales se presenta en el comercio, como contrabando en su faceta exterior y como "mercado negro-comercio ambulante" en su faceta interna, siendo ambos, dos eslabones de la misma cadena, lo que plantea el desafío de incorporar a la población que desarrolla estas actividades a la formalidad.

Esta realidad distorsiona y debilita la capacidad de negociación comercial externa, ya que en los hechos existe ya arancel 0 , para lo que quizás podría ser la mitad de las importaciones reales. Los aranceles en Bolivia desde hace mucho tiempo han dejado de ser un verdadero instrumento de protección a la industria nacional.

Por otra parte, las actividades ligadas al tráfico de drogas, aunque muchas veces sobredimensionadas, son de profundo impacto interno y de gran relevancia en la vinculación externa. En los últimos años, el narcotráfico -fenómeno de complejas implicancias económicas, de dimensiones socio-políticas y alcance internacional- es un factor que en gran medida ha estado condicionando (y distorsionando) la imagen, acción y relación externa del país. Por ello, analizaremos su impacto real en la estructura productiva nacional.

Bolivia es un país que tradicionalmente ha producido hoja de coca para su consumo interno, sin embargo durante las últimas dos décadas de manera creciente se ha incrementado su producción, insertándose a los circuitos del tráfico ilegal de cocaína. Este proceso ha generado una

\footnotetext{
${ }^{14}$ Presencia, La Paz, 9 de septiembre de 1992, p. 6.

${ }^{15} \mathrm{Hoy}, \mathrm{La}$ Paz, 18 de febrero de 1993, p. 9.

${ }^{16}$ Cámara de Industria de Cochabamba, El Industrial, Año 6, Nº72, febrero de 1993, p. 14.

${ }^{17}$ Federico Csapek, en: FUNDEMOS, "Una solución estructural al contrabando en Bolivia", La Paz, julio de 1989, pp. 30-33.
} 
"economía de la hoja de coca", que es la interelación de la producción de hoja de coca con otros sectores económicos. Si bien ésta no constituye necesariamente narcotráfico per se, su conexión final con éste ha hecho que se genere una actividad muy dinámica y altamente rentable.

Como toda economía subterránea, es muy difícil cuantificar con precisión el real volumen e impacto de la economía de la hoja de coca, que para unos está en declinación y para otros está en franco crecimiento. Inclusive el éxito de la estabilidad económica nacional estaría condicionado al narcotráfico. ${ }^{18}$

Enunciaremos algunas estimaciones, a fin de mostrar la magnitud de su importancia. Datos publicados en 1990, por la Presidencia de la República de Bolivia, muestran que las diferentes etapas de la producción de coca y derivados generan un valor agregado de 1.422 millones de dólares(24\% del PIB). Sin embargo solamente se estima que alrededor de 500 millones de dólares permanecerían en el país; el resto constituiría fuga de capitales. ${ }^{19}$

Según estimaciones más actualizadas presentadas en 1994 por el Ministerio de Desarrollo Sostenible, a nivel general en la economía nacional, el valor agregado directo de la economía de la coca declinó desde $9 \%$ del PIB en 1988 hasta el 3\% del mismo en 1993. Con relación a las exportaciones, en 1988 la cocaína representó el 84\% de las exportaciones (453 millones de dólares) y en 1993 disminuyó al 24\% (171 millones de dólares). ${ }^{20}$

Las estimaciones por el lado de los mismos productores de hoja de coca dicen que "la coca es fuente y origen para la generación de aproximadamente 400 millones de dólares que se quedan en Bolivia como saldo de la economía de este vegetal y su influencia en el aparato productivo se expresa en un $7 \%$ de participación global en la actividad económica nacional". ${ }^{21}$ Se estima que la economía de la coca absorbe a 300 mil habitantes, $5 \%$ de la población del país y 10\% de la PEA, que

\footnotetext{
${ }^{18}$ Según el economista peruano Oscar Ugarteche, la estabilidad de la economfa boliviana se basa en recursos generados por el narcotráfico y en la austeridad fiscal. Presencia, La Paz, $24 \mathrm{de}$ noviembre de 1989.

${ }^{19}$ Presidencia de la República de Bolivia, Esirategia Nacional de Desarrollo Alternativo, La Paz, 1990.

${ }^{20}$ José Guillermo Justiniano, "La problemática coca-cocaina en Bolivia", Ministerio de Desarrollo Sostenible y Medio Ambiente. Documento presentado ante el Grupo Consultivo de Paris, 2 de noviembre de 1994.

${ }^{2 \mathrm{I}}$ Según datos proporcionados por Gregorio Lanza, Asesor Técnico de los Productores de Hoja de Coca. LOS TIEMPOS, Cochabamba, 8 de diciembre de 1994, p. A9.
} 
perciben aproximadamente 171 millones de dólares por año. ${ }^{22}$ Aunque, hay otros investigadores que sobrestiman su peso, manifestando que "la economía de la coca podría representar en Bolivia más del 20\% del PIB y emplear a un $20 \%$ de la $\mathrm{PEA}$. ${ }^{23}$

La producción mundial de coca se concentra en tres países cuya participación en 1984 se preveía en hectáreas plantadas: Perú producía 100.000 , Bolivia 60.000 y Colombia 25.000. Sin embargo, diez años después estos volúmenes de producción sufren cambios sustanciales. La producción de hoja de coca por hectáreas en 1994 muestra que Perú produce más de 200.000 , Colombia 85.000 y Bolivia aproximadamente $45.000 .{ }^{24}$ Es decir, según la información oficial, mientras los otros países andinos han incrementado su producción, Bolivia ba reducido sus siembras de este producto y esto muestra también que los carteles extranjeros de narcotráfico han reducido relativamente su dependencia de los suministros bolivianos. Aunque la economía boliviana, dado su estrechez, depende del circuito coca-cocaína más que la de los otros dos países productores, existe la tendencia a disminuir tal influencia. Al parecer, el proceso de declinación del peso de la economía de la coca con relación a la economía nacional no se debería a que la economía boliviana esté creciendo, expandiendo y diversificando, sino por un efecto sustitutivo de factores externos.

La evolución histórica de la economía boliviana y su integración al comercio mundial han estado marcadas por los ciclos de auge, agotamiento o sustitución de un determinado recurso natural. Al parecer, la coca no se escapa de esta tendencia, de manera similar a lo que sucedió con el estaño durante este siglo y con la plata la centuria pasada.

Como se ha visto, en el marco de la economía subterránea se producen exportaciones ilegales, que generan una capacidad extra de importación informal, muy por encima de la capacidad para importar formalmente generada por las exportaciones oficiales. Es decir, los excedentes del narcotráfico generan una capacidad extra de consumo que estaría financiando en gran medida el contrabando.

22 Datos del CEDIB mencionados por Raúl Maidana, "Opción cero provocará colapso económico", Presencia, 13 de octubre de 1994.

${ }^{23}$ Dario Betancur y Martha Garcia "Contrabandistas, Marimberos y Mafiosos", LA RAZON, La Paz, 29 de septiembre de 1994.

24 "Colombia desplazó a Bolivia en producción de hoja de coca", LOSTIEMPOS, Cochabamba, 13 de octubre de 1994. 


\section{Nueva Política Económica y política comercial.}

En estos últimos años Bolivia ha modificado sustancialmente su estrategia de desarrollo, orientándose a un modelo sustentado en la liberalización comercial, apertura externa y promoción de las exportaciones. Los mayores logros de la NPE se refieren a la estabilización macroeconómica, que era su objetivo de corto plazo; sin embargo, están en cuestionamiento los de largo plazo, que son los relativos al cambio estructural y autosustentabilidad económica. En los 10 años de vigencia de la NPE las más importantes transformaciones se han haciendo efectivas lentamente, no habiéndose encarado políticas orientadas a acelerar la transformación productiva, por lo que tampoco se ha superado el ya crónico y persistente déficit en la balanza de pagos, que continuamente está siendo financiado básicamente por la cooperación económica internacional, situación que agrava la situación de dependencia externa.

Dado el carácter estrecho, deprimido y pequeño de la economía boliviana, el mercado mundial ofrece oportunidades de crecimiento vía exportaciones. Sin embargo, está costando un gran esfuerzo la adaptación del aparato productivo interno a la nueva realidad del sector externo.

Los principales cambios que la NPE posibilita en la política comercial buscan asegurar la apertura externa, superando los supuestos del modelo de sustitución de importaciones y abriendo la economía nacional al comercio internacional. La NPE introduce un cambio radical en la política comercial, con una drástica reducción de tarifas arancelarias tendiendo a su uniformización. Por el lado de las importaciones, la política arancelaria se basa en dos tipos de tasas: una del 5\% para importaciones de bienes de capital y otra del $10 \%$ para los demás bienes. Se ha abolido la mayor parte de barreras no arancelarias, excepto aquellas necesarias para proteger la salud pública y seguridad del país. La apertura a las importaciones es en gran medida formal, dado que los grandes volúmenes de contrabando hace que en los hechos e informalmente ingresen al país una infinidad de productos con arancel 0.

Por el lado de las exportaciones, se busca promover su expansión y competitividad. Con esta finalidad la Ley de Desarrollo y Tratamiento Impositivo a las Exportaciones, dentro del concepto de "neutralidad impositiva", dispone la devolución de impuestos internos y aranceles incorporados en los insumos de las mercaderías exportadas. También se establece un sistema de zonas francas industriales y comerciales, así 
como un régimen de ingreso temporal de mercaderías para su posterior reexportación. Con el mismo fin, se procura mantener un tipo de cambio real, flexible y estable.

Consideramos que la política de apertura comercial no puede limitarse solamente a la rebaja o eliminación de barreras arancelarias y no arancelarias u otro tipo de medidas de tipo comercial o de corte fiscal. Dado el carácter neutro de la NPE, existe una carencia de políticas públicas destinadas a promover actividades sectoriales que presenten potencialidades de expansión exportadora. Desde 1985 ha existido una política de promoción de exportaciones errática, limitada y centrada en la devolución de los impuestos. Si bien esta medida contribuye a revertir los sesgos antiexportadores del modelo, se reduce a una visión tributaria del problema y no acomete de manera focalizada la reconversión industrial y modernización del aparato productivo, que son la base para la competitividad de un país. En efecto, el Programa de Ajuste estructural implementado en Bolivia carece actualmente de una política industrial cuyo objetivo sea el desarrollo de ventajas competitivas dinámicas y la adecuación de los sectores existentes a las nuevas condiciones de la competitividad en los mercados internacionales. ${ }^{25}$

Desde la implementación de la NPE, el comportamiento del comercio exterior se agravó, ya que ha ido configurando un crónico proceso deficitario de la balanza comercial al existir una tendencia con ciertas oscilaciones a la inestabilidad de las exportaciones y al incremento sostenido de importaciones, que son financiadas mediante la cuenta de capital con endeudamiento externo y financiamiento extraordinario, lo que es insostenible en el largo plazo.

\footnotetext{
${ }^{25}$ Alfredo Seoane Flores, "Los Acuerdos Comerciales y la Estrategia de Desarrollo mediante Exportaciones", Ministerio de Relaciones Exteriores/UDAPEX, (mimeografiado-versión preliminar), La Paz, 15 de noviembre de 1994, p. 12. Véase también el acápite sobre Apertura Externa y cl Sector Industrial Boliviano, en el trabajo de Gabriel Loza Lineamientos para la Modernización Industrial en Bolivia, Bases para la Modernizacion Industrial en Bolivia, PCAB, La Paz, 1991, pp.
15-19.
} 


\section{Bolivia: evolución de la balanza comercial} (en millones de dólares)

$\begin{array}{cccc}\text { Años/Productos } & \text { Exportación } & \text { Importación } & \text { Saldo Total } \\ 1985 & 628,4 & 690,9 & -62,5 \\ 1986 & 587,5 & 674,0 & -86,5 \\ 1987 & 518,7 & 766,3 & -247,6 \\ 1988 & 553,2 & 590,5 & -37,3 \\ 1989 & 745,7 & 610,9 & 134,8 \\ 1990 & 845,2 & 687,2 & 158,0 \\ 1991 & 776,6 & 969,5 & -192,9 \\ 1992 & 637,6 & 1.090,3 & -452,7 \\ 1993 & 709,7 & 1.205,9 & -496,2 \\ 1994 & 1.104,0 & 1.207,0 & -102,0 \\ 1995 & 1.041,5 & 1.393,4 & -351,9 \\ 1996^{*} & 478,1 & 682,7 & -204,6\end{array}$

Fuente: Banco Central de Bolivia, Boletín del Sector Externo, №15, La Paz, junio de 1996, p. 11.

$\left({ }^{*}\right)$ Estimación para enero-junio/96.

A partir de 1985, año en que se introduce la NPE, la liberalización del comercio exterior ha provocado un sustancial incremento de las importaciones; sin embargo, las exportaciones han tenido un comportamiento arrítmico, fluctuante y rezagado, lo que genera dicho déficit comercial.

El saldo de la balanza comercial ha tenido índices negativos durante casi los últimos diez años, exceptuando las gestiones de 1989-1990. El comportamiento irregular de las exportaciones totales se debe a la caída de las exportaciones tradicionales en minería e hidrocarburos, así como al deterioro de los precios de algunos productos agrícolas y al carácter volátil de otros. Sin embargo, cabe destacar el dinamismo que adquieren las exportaciones no tradicionales, que crecientemente están incrementando su participación en el total, así como su paulatina diversificación tanto en productos como mercados. Al respecto, cabe mencionar que mientras en 1985 se exportaban 82 productos no tradicionales, en 1994 se exportaron 341. Mientras que las exportaciones no tradicionales en 1986 se dirigieron 35 países, en 1994 tuvieron 62 países de destino.

Indudablemente el eje central para el éxito de un modelo de desarrollo hacia afuera es el dinamismo exportador. La NPE ha implicado un cambio profundo en la concepción misma de la política comercial. Sin 
embargo, pese al drástico cambio de políticas, las transformaciones en la estructura productiva son más lentas. Bolivia sigue siendo un país donde priman las exportaciones menos dinámicas como minerales e hidrocarburos.

En Bolivia, se está dando una difícil contradicción, ya que coexisten un alto grado de apertura externa oficial y un bajo nivel de competitividad internacional. La acelerada liberalización del comercio exterior impulsada por un activismo gubernamental en el frente externo no es acorde al ritmo gradual de un proceso pasivo de reconversión del aparato productivo nacional, lo que está generando una creciente globalización. de las importaciones y un lento posicionamiento de las exportaciones en productos y mercados externos de bajo dinamismo.

Pese a la apertura formal e irrestricta, en la realidad la economía boliviana constituye una economía de tipo centrípeta, localista, importadora y de inserción pasiva. ${ }^{26} \mathrm{La}$ creciente apertura externa no está siendo acompañada por incrementos en la competitividad interna. Consideramos que en el largo plazo la única forma de viabilidad de un modelo de desarrollo hacia afuera es consolidando una economía centrífuga, abierta, productiva, internacionalizada y exportadora, cuyo peso relativo de los flujos comerciales y financieros de salida al mundo externo contribuyan equilibrada, positiva y significativamente al crecimiento sostenido del producto nacional.

\section{Conclusiones.}

Como se ha visto a lo largo de este estudio un conjunto de variables de tipo interno conspiran contra una inserción boliviana más competitiva y dinámica en el comercio internacional. La naturaleza de estas condicionalidades internas hacen que el desarrollo nacional sea altamente dependiente de factores externos, por lo que consideramos que la mejor vía para lograr tal desarrollo es construyendo un entramado de relaciones

\footnotetext{
${ }^{26}$ Entiéndase "centrípeta" como introvertida, parcial, deficitariamente internacionalizada y centrada en el mercado interno, donde prima una mentalidad rentista sobre la productividad y la competitividad, ya que si bien la apertura formal del comercio exterior posibilitó el crecimiento importador (su participación porcentual en el PIB se duplicó del $-15,9 \%$ en 1983 al $-32,4$ en 1993), los flujos exportadores reales no se expanden proporcionalmente, ni se articulan dinámicamente en los centros de comercio mundial. Es más, las exportaciones bolivianas representaron en $1993 \mathrm{el}$ $29 \%$ del PIB, siendo que las mismas en 1983 participaron en el PIB con $28,4 \%$, año antes de que detonara la crisis del modelo estatista y sustituidor de importaciones. Es decir, el nivel de internacionalización vía exportaciones no ha variado mucho en un contexto de apertura externa formal. B.C.B., Boletin Estadistico, N2280, La Paz, diciembre de 1993, p. 134.
} 
externas que permitan generar flujos positivos para la economía nacional que compensen las insuficiencias internas.

Una estrategia de inserción en los mercados globales pasa por una estrategia de desarrollo industrial e innovación tecnológica. Crear una estructura productiva y competitiva es el vehículo para superar nuestro modo de inserción declinante, deficitario e inclusive delincuencial, que no hace otra cosa que acentuar la marginalidad del país.

En suma, Bolivia es una sociedad compleja, cuya economía frágil, pequeña y dual, está sustentada predominantemente en la explotación y exportación de recursos naturales, así como en la importación de manufacturas de mayor valor agregado. Su situación mediterránea, infraestructura física y productiva insuficiente, carencias tecnológicas, debilidades institucionales, entre otros elementos, determinan una inserción internacional pasiva, segmentada, deficitaria, declinante, dependiente y vulnerable. Esto hace que la economía boliviana se encuentre cada vez más marginada de los principales circuitos del comercio internacional crecientemente globalizado. 